\title{
Erratum to: "Establishing New Acceptance Limits for Dissolution Performance Verification of USPC Apparatus I and 2 Using USPC Prednisone Tablets Reference Standard"
}

Anthony J. DeStefano $\cdot$ Walter W. Hauck • Erika S. Stippler • William E. Brown • Chensheng Li • Gloria G. Huang • Barbara J. Jones $•$ Kevin O'Hool $•$ William F. Koch $・$ Roger L. Williams

Published online: 1 February 2011

(C) Springer Science+Business Media, LLC 2011

\section{Erratum to: Pharm Res}

DOI $10.1007 /$ s11095-010-0295-3

We regret that the original article duplicated Figure $5 \mathrm{a}$ and omitted Figure 5b. The figures and caption should have been published as shown here.

The online version of the original article can be found at http://dx.doi.org/ | 0. 1007/s | |095-0 10-0295-3.

A. J. DeStefano $(\bowtie) \cdot$ W. W. Hauck $\cdot$ E. S. Stippler $\cdot$ W. E. Brown $\cdot$ C. Li $\cdot$ B. J. Jones $\cdot$ K. O'Hool $\cdot$ W. F. Koch $\cdot$ R. L. Williams

US Pharmacopeial Convention

Rockville, Maryland 20852, USA

e-mail: ajd@usp.org

Present Address:

G. G. Huang

US Food and Drug Administration

Silver Spring, Maryland, USA

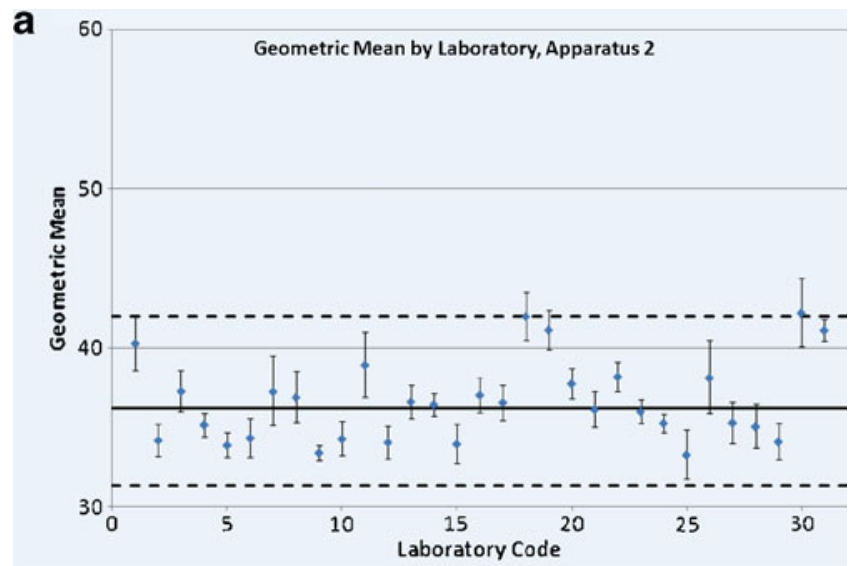

b

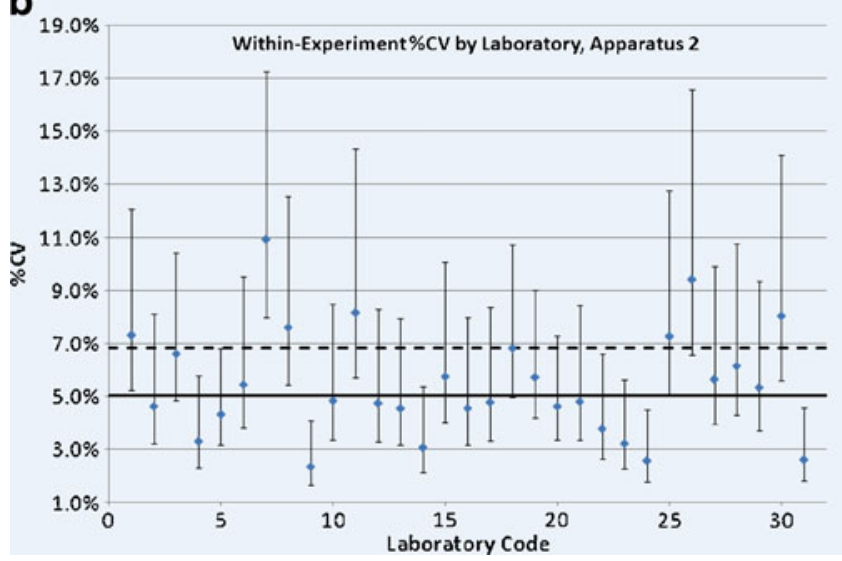

Fig. 5 GM and \%CV by Laboratory, Apparatus 2. Error bars are $95 \%$ confidence intervals based on each laboratory's between-position variability. Horizontal lines are the combined value from the collaborative study and the single-stage Lot PI PVT limits for an instrument with six positions. Limits for seven- and eight-position instruments are tighter. The limits for the geometric mean are those at the time of the collaborative study 